\title{
Potentials of endogenous neural stem cells in cortical repair
}

\section{Bhaskar Saha*, Mohamed Jaber and Afsaneh Gaillard}

Experimental and Clinical Neurosciences Laboratory, Cellular Therapies in Brain Diseases group, INSERM U1084, University of Poitiers, Poitiers, France

\author{
Edited by: \\ Arianna Maffei, SUNY Stony Brook, \\ USA
}

\section{Reviewed by:}

Shaoyu Ge, SUNY Stony Brook, USA Harold Cremer, Centre National de La Recherche Scientifique, France

\section{*Correspondence:}

Bhaskar Saha, Experimental and Clinical Neurosciences Laboratory, Cellular Therapies in Brain Diseases group, INSERM U1084, University of Poitiers, 1, Rue Georges Bonnet, BP 633, Poitiers F-86022, France. e-mail: bhaskar.saha@univ-poitiers.fr
In the last few decades great thrust has been put in the area of regenerative neurobiology research to combat brain injuries and neurodegenerative diseases. The recent discovery of neurogenic niches in the adult brain has led researchers to study how to mobilize these cells to orchestrate an endogenous repair mechanism. The brain can minimize injury-induced damage by means of an immediate glial response and by initiating repair mechanisms that involve the generation and mobilization of new neurons to the site of injury where they can integrate into the existing circuit. This review highlights the current status of research in this field. Here, we discuss the changes that take place in the neurogenic milieu following injury. We will focus, in particular, on the cellular and molecular controls that lead to increased proliferation in the Sub ventricular Zone (SVZ) as well as neurogenesis. We will also concentrate on how these cellular and molecular mechanisms influence the migration of new cells to the affected area and their differentiation into neuronal/glial lineage that initiate the repair mechanism. Next, we will discuss some of the different factors that limit/retard the repair process and highlight future lines of research that can help to overcome these limitations. A clear understanding of the underlying molecular mechanisms and physiological changes following brain damage and the subsequent endogenous repair should help us develop better strategies to repair damaged brains.

Keywords: subventricular zone, proliferation, migration, lesion

\section{INTRODUCTION}

In 1848, an almost fatal accident occurred to an American railroad worker, Phineas P. Gage, when a large iron rod went through his forehead leading to the destruction of most of his left frontal lobe. This has created an immense stir in the field of neurobiology, particularly brain injury, as it was the first evidence that damage to the brain can lead to changes in personality and behavior. In the second half of the nineteenth century, a major fundamental dogma of neuroscience pertaining to Central Nervous System (CNS) damage evolved when Paul Broca introduced the concept of neuronal plasticity. He postulated that the right hemisphere can function as an alternative speech center when the actual center in the left hemisphere is absent. Although the concept of neuronal plasticity attempted to address the issue of functional compensation after injury, it could not provide any answer to how a damaged area could be repaired by healthy cells to attain sustained recovery. This led to the beginning of the era of tissue transplantation to replace injured tissue. The first attempt at brain tissue transplantation was performed in 1890 by WG Thompson. The occipital brain tissue from an adult dog was transplanted homotypically into another dog and survival of the transplanted tissue within the host was reported after 7 weeks (Thompson, 1890). Several attempts of tissue transplantation (both successful and unsuccessful) were then carried out in the first half of twentieth century using mature, neonatal, and even embryonic CNS tissue (for review see Dunnett, 2009).
Transplantation studies were an important historical milestone for tissue/cell replacement therapy in response to brain injury. But, another fundamental question that remained unanswered was whether the brain on its own could repair damage caused by an injury. This is primarily because of the initial general belief that new neurons are not generated in adults. A 100 years following Broca's postulation, Joseph Altman and Gopal Das first described the presence of a large pool of germinal cells in the wall of the third and lateral ventricle in adult brain (Altman and Das, 1962). Using thymidine- $\mathrm{H}^{3}$ incorporation in the hippocampus of young adult rats they established the evidence for neurogenesis in the adult brain. They also showed that neurogenesis occurs in the sub ventricular zone (SVZ) where newborn progenitor cells are generated and then move to the olfactory bulb (OB) through the Rostral Migratory Stream (RMS). Later, in the 1990s, by injecting lacZ expressing retroviral tracer into the neonatal rat SVZ (Luskin, 1993) and by grafting $\beta$-gal expressing donor SVZ cells into normal mice (Lois and Alvarez-Buylla, 1994), it was convincingly shown that progenitor cells migrate through a restricted pathway to the $\mathrm{OB}$ and differentiate into granule and periglomerular cells. Ultra structural analysis of the SVZ in mammals established that the germinal zone in the adult consists of three cell types: type " $\mathrm{B}$ " cells are astrocytes and are considered as the "stem cells" that form transiently proliferating type "C" cells, which in turn generate type " $\mathrm{A}$ " neuroblasts that migrate along the RMS to the OB (Doetsch et al., 1997). Functional relevance 
of adult neurogenesis was established from studies in songbirds, where seasonal turnover of neurogenesis and recruitment of new cells to the song control nuclei was found to be correlated with seasonal song learning behavior (Alvarez-Buylla and Nottebohm, 1988; Alvarez-Buylla et al., 1988; Scharff et al., 2000; Barnea and Pravosudov, 2011).

The discovery of neural stem cell niches in the adult brain has raised the possibility of endogenous neuronal replacement after injury or disease. It is now established that following CNS injury, a plethora of changes in the brain takes place at the proliferative niche, the SVZ and also near the damaged area. Different classes of molecules such as trophic factors, morphogens, cytokines, and other cell signaling molecules have been identified as key players regulating this process. Studies have shown that vasculature and neuroblast migration patterns go hand-in-gloves. In response to neuronal damage the vasculature pattern is changed in the cortex and this can be correlated with changes in the migration of the progenitor cells. In this review, we will discuss recent findings about the physiological and molecular aspects of generation of new neurons, their migration to the lesion site and integration into the existing circuitry. Our main focus is on cerebral cortex lesion/injury, which we discuss with reference to cerebral ischemia, an injury model that has been studied extensively. We will also discuss the limitations of endogenous repair and, therefore, the necessity of cell/tissue transplantation as a measure of cell replacement therapy.

\section{BRAIN INJURY AND NEUROGENIC NICHE PROLIFERATION}

In a normal adult brain, two distinct regions continuously proliferate to generate new neurons, the SVZ and the sub granular zone (SGZ) of the hippocampus. We will discuss here the changes occurring in the SVZ after an injury to the cerebral cortex. Studies using different models of experimental lesions in the cerebral cortex suggest that injury leads to an increase in the SVZ cell proliferation. These include controlled cortical impact (CCI) (Ramaswamy et al., 2005); fluid-percussion injury (FPI) (Carbonell et al., 1998; Chirumamilla et al., 2002; Chen et al., 2003); aspiration lesions (Szele and Chesselet, 1996) and focal acute injury (FAI) (Blizzard et al., 2011). Despite a general agreement that cortical lesions result in an increase in cell proliferation within the SVZ, observations on finer aspects of proliferation are somewhat contradictory. For instance, it is still debated whether unilateral brain damage leads to higher proliferation in both hemispheres and whether this proliferation is a long-term/persistent or a short-term/transient change. Enhancement of cell proliferation in both the ipsilateral and contralateral SVZ, relative to the site of injury, was observed in an FPI model (Chen et al., 2003) as well as in intracerebral hemorrhage (Masuda et al., 2007) in rats. In contrast, another study using CCI model reported that proliferation was observed only in the ipsilateral hemisphere 3 days after injury (Ramaswamy et al., 2005). One of the possible reasons for this discrepancy is that changes in the SVZ following lesion is not instantaneous, but gradual. Therefore, the 3 days post-injury time (as mentioned in Ramaswamy et al., 2005) may just be too short to induce changes in the contralateral SVZ after lesion. Increases in the proliferation were also reported to be persistent (three to sixfold increase in the proliferation was observed in lesion animals) and last up to 1 year after lesion (Chen et al., 2003). This observation suggests that although aging reduces the capacity of SVZ proliferation in normal adults, the factors necessary for proliferation continue to be present (probably in a dormant state). Cortical lesion can reactivate these factors leading to an increase in proliferation. Contrary to previous observations mentioned above, Goings et al. (2002) have reported a biphasic reduction in the SVZ proliferation following aspiration lesions in the mice cerebral cortex. The authors suggested that the reduction in the SVZ proliferation is possibly due to a reduction in serotonergic neurotransmission following lesion as serotonin can increase SVZ proliferation (Banasr et al., 2004). However, this conclusion is not in line with a previous report indicating that extracellular release of serotonin is increased in the cortex following traumatic brain injury (TBI) (Busto et al., 1997).

Available literature till date clearly indicates an increase in the SVZ progenitor proliferation in response to cortical lesions. However, variations in the observation by different groups call for an explanation. Previously, it has been suggested that the observed differences in the SVZ proliferation (increased vs. reduced) may be due to species variation where rats, but not mice, exhibit an increased proliferation (Romanko et al., 2004). However, this explanation is not satisfactory as CCI lesion model in mice also showed an increase in SVZ proliferation (Ramaswamy et al., 2005). A more probable reason may be that the extents of damage in different lesion paradigms are different and can result in variations in molecular responses both near the lesion area as well as the SVZ leading to differences in the SVZ cellular proliferation.

\section{DOES ENHANCED PROLIFERATION RESULT IN NEW NEUROGENESIS?}

Neurogenesis in the SVZ above basal level is an important prerequisite for neuronal replacement after injury. Experimental data being scarce, it is as of yet still not clear whether increased proliferation leads to increased neurogenesis in the SVZ after cortical lesion. Sundholm-Peters et al. (2005), using BrDU and doublecortin (Dcx, a neuroblast marker) immunostaining in mice, reported no significant increase in $\mathrm{BrDU}+/ \mathrm{Dcx}+$ cell number in the SVZ 15 days after an aspiration lesion suggesting that there is no enhancement in neurogenesis in the SVZ. On the contrary, a previous finding by the same group demonstrated a delayed increase (after 25 days of lesion) in the number of PSA-NCAM (neuroblast marker) positive cells in the SVZ (Goings et al., 2002). A temporal difference in the generation of different cell types in the SVZ cannot be ruled out and it is possible that most of the early proliferating cells contribute to astrocytes generation whereas neurogenesis starts at a later time point. The knowledge of enhancement of neurogenesis within the SVZ is promising and constitutes an important initial step toward endogenous repair process. However, effective repair strategies do require that these neuroblasts migrate to the injured area, differentiate into mature neuron and integrate into the existing circuitry.

\section{DO NEW NEURONS FORM IN THE CORTEX AFTER LESION?}

It is established that the cerebral cortex of normal adults is nonneurogenic (Kornack and Rakic, 2001; Koketsu et al., 2003; Rakic, 2004; Bhardwaj et al., 2006). Several groups have reported that 
in response to either TBI (Magavi et al., 2000; Dash et al., 2001; Lu et al., 2003; Rice et al., 2003; Covey et al., 2010; Vessal and Darian-Smith, 2010) or stroke (Jiang et al., 2001; Arvidsson et al., 2002; Parent et al., 2002; Jin et al., 2003; Zhang et al., 2006; Leker et al., 2007; Masuda et al., 2007; Ziv et al., 2007), neurogenesis can be induced in non-neurogenic areas such as the cortex. Magavi et al. (2000) argued that proliferation occurs both in normal and injured cortex. In normal cortex most of these dividing cells form glia, remain undifferentiated or undergo apoptosis. However, after degeneration of layer VI corticothalamic projection neurons, some of the new neurons in the cortex were found to be derived from precursors present in the cortex, while some originated from the nearby SVZ. A few recent studies used more direct approaches to ascertain that these new neurons are indeed generated in the cortex. Application of Cytosine Arabinosine [(Ara-C), which blocks SVZ "type C" cell proliferation] for 7 days post-ischemia resulted in a reduction, but not complete absence of proliferative response around peri-infarct area and almost 15\% of those proliferating cells were non-microglial and nestin positive (Leker et al., 2007). In another study, 3 days after a unilateral infrared-laser lesion in the rat visual cortex, BrDU positive cells, which also expressed cell surface 473HD-epitope (a marker for embryonic and adult neural progenitor cells), were found to be around the lesion penumbra (Sirko et al., 2009). The 3 day time window is not long enough for cells to generate in the SVZ and migrate to the visual cortex in response to lesions. In non-human primates, newborn mature neurons in the somatosensory cortex exhibit multiple neuronal phenotypes (Vessal and Darian-Smith, 2010). Indeed, BrDU-positive newborn neurons were shown to co-express NeuN, calbindin, and GABA. Although a majority of the neurons are presumably inhibitory (due to the smaller size of their soma), a small percentage of pyramidal neurons could also be found. Taken together, these reports demonstrate that endogenous neural precursors can be induced in non-canonical neurogenic regions to differentiate into CNS neurons in a regionspecific manner.

Contrary to this view, the contribution of SVZ-derived cells in cortical neurogenesis following ischemia was established convincingly by using 5 HT3A-GFP mice where GFP is expressed by postnatal SVZ-derived cells (Kreuzberg et al., 2010). GFP labeling together with BrDU incorporation revealed that following ischemic lesion, new neurons in the cortex are in fact derived from the SVZ. In a more recent study, focal injury in the somatosensory cortex of rats resulted in generation of astrocytes and microglia/macrophages, but no mature neurons in the neocortex near the lesioned area (Blizzard et al., 2011). Thus, a clear determination of whether SVZ is the only source of new neurons in TBI or stroke-induced lesion is lacking. Direct approaches, such as delivery of viral vector-mediated markers into SVZ cells and following their migration in real time using various microscopic techniques may yield more convincing results to ascertain the source of new neurons near the injury.

\section{MOLECULAR CHANGES REGULATING SVZ PROLIFERATION AFTER LESION}

In normal adults, both cell-intrinsic and extrinsic molecules have been described to regulate the proliferation of the neurogenic niche. These molecules range from morphogen (Shh, Wnts), growth factors such as Epidermal Growth Factor (EGF), Fibroblast Growth Factor (FGF), Tissue Necrosis Factor- $\alpha$ (TNF- $\alpha$ ), Hepatocyte Growth Factor (HGF), neurotransmitters (Neuropeptide Y, Dopamine), nuclear orphan receptor (Tlx), transcription factor (Sox2) and cell surface molecules such as Notch1 (Coronas et al., 2004; Decressac et al., 2009; Nicoleau et al., 2009; Xiao et al., 2009; Mu et al., 2010). Analyzing the expression pattern of these regulatory molecules following cortical injury will be crucial in indicating their involvement in regulating post-injury cell proliferation/neurogenesis at the level of SVZ. Expression of bFGF is increased transiently in neurons present in the cortical layer VIb of fronto-parietal cortex in rats after aspiration lesion (Gómez-Pinilla and Cotman, 1992), but functional significance of such changes is yet unknown. Five days after aspiration lesion in the cortex, expression of EGF receptor (EGFr), FGF receptor (FGFr), erbB3 (a neuregulin receptor) and DCC (Deleted in Colorectal Cancer) remained unchanged in the SVZ, whereas EGF expression was found to be increased near the lesion area, in the corpus callosum and in the SVZ (Sundholm-Peters et al., 2005). The authors did not comment on the role of EGF signaling in SVZ cell proliferation, but this change in expression was attributed to the chemotactic property of EGF, which might be responsible for ectopic neuroblast migration. Contrary to this observation, EGFr expression (both mRNA and Protein) was shown to increase transiently by threefold after ischemic lesion in neonatal rats without any concomitant change in its ligand (EGF mRNA) expression (Alagappan et al., 2009). In addition, a 50\% reduction of Transforming Growth Factor- $\alpha$ (TGF $\alpha)$, one major ligand of EGFr, was observed. The functional relevance of EGFr overexpression lies in the recruitment of cells into the cell cycle and reduction of cell cycle time. Several studies have demonstrated that exogenous application of various growth factors like BDNF, FGF2, GDNF, IGF1, VEGF increase ischemia-induced neurogenesis in animal models (Watanabe et al., 2004; Baldauf and Reymann, 2005; Tureyen et al., 2005; Schäbitz et al., 2007) and thus helps reducing the size of infarct volume. Expression of these molecules is enhanced in animal models of ischemia (Dempsey and Kalluri, 2007). These molecules, in principal, play an important neuroprotective role either by increasing cell proliferation, cell survival or both.

Among different morphogens, Sonic hedgehog (Shh) and Wnts are important signaling molecules controlling cell proliferation. In a cortical freeze injury model, Shh activity is transiently increased in the cortex with a peak at 3 days after lesion. Shh induces reactive gliosis in a Gli-dependent manner and also regulates proliferation of Olig2-positive cells in the injured cortex (Amankulor et al., 2009). In response to ischemia, Shh increases proliferation in the hippocampal proliferative niche while administration of Shh antagonist inhibits the process (Sims et al., 2009). Shh level is also upregulated in the SVZ within $24 \mathrm{~h}$ after ischemia (Wang et al., 2009). This upregulation is probably mediated by increased expression of the activated form of Notch1 (Notch intracellular domain, NICD) in response to ischemia, as Shh is a downstream transcriptional target of NICD. Therefore, although there is no direct evidence describing the role 
of Shh in the SVZ proliferation following injury, the possibility cannot be ruled out. Unlike Shh, expression of Wnt family genes is not upregulated after ischemic injury in rats (Morris et al., 2007), indicating that these genes may not be involved in injury-induced proliferation. Nevertheless, Wnt pathway seems to indirectly regulate remyelination process in human demyalination damages through one of its targets, AXIN2 (Fancy et al., 2011).

\section{INJURY-INDUCED ECTOPIC MIGRATION OF SVZ-DERIVED NEUROBLASTS}

In normal physiological condition, neuroblasts (type "A" cells) generated in the SVZ migrate tangentially along the RMS to the $\mathrm{OB}$, where they differentiate into either granule cells (GC) or periglomerular cells (PG). Astrocytes form a "glial tube" surrounding the neuroblasts, which is believed to restrict them from migrating ectopically to other brain regions. Studies have shown that in several pathological conditions these cells can migrate out of the RMS to reach to the affected brain areas (see Table 1). Among these, ectopic cell migration in response to cerebral ischemia has been studied most extensively, where cells were demonstrated to reach the affected striatum following experimental Medial Cerebral Artery Occlusion (Arvidsson et al., 2002; Jin et al., 2003; Sundholm-Peters et al., 2005; Kokaia et al., 2006; Ohab et al., 2006; Yamashita et al., 2006; Cayre et al., 2009; Young et al., 2011). Huntington's disease, which predominantly affects striatal spiny neurons, triggers migration of neural progenitors from the SVZ to the affected area (Tattersfield et al., 2004). Similarly, neuroblasts migration from the SVZ to the damaged cerebral cortex is also documented after TBI (Figure 1) (Goings et al., 2004; Ramaswamy et al., 2005). On the other hand, such ectopic migration of neural progenitors to damaged areas is neither reported in Parkinson's disease nor in Alzheimer's disease. The inability of ectopic migration could possibly be linked to reduced proliferation in the SVZ in these diseases. This notion is supported by a previous work demonstrating that the exogenous application of EGF and FGF2 can enhance SVZ proliferation and trigger neuroblast migration to the dopamine deficit area in Parkinson's disease (Winner et al., 2008). In the normal adult brain, tangential migration of neuroblasts in consortium along the RMS is termed "chain migration"

Table 1 | In different neurodegenerative diseases SVZ proliferation either increases $(++)$ or decreases $(--)$.

\begin{tabular}{|c|c|c|c|}
\hline Diseases & $\begin{array}{l}\text { SVZ } \\
\text { Proliferation }\end{array}$ & $\begin{array}{l}\text { Migration to } \\
\text { damaged area }\end{array}$ & $\begin{array}{l}\text { Selected } \\
\text { references }\end{array}$ \\
\hline Huntington & ++ & ++ & $\begin{array}{l}\text { Tattersfield et al., 2004; } \\
\text { Decressac et al., } 2010\end{array}$ \\
\hline Parkinson & -- & $? ?$ & Hoglinger et al., 2004 \\
\hline Ischemia/stroke & ++ & ++ & $\begin{array}{l}\text { Arvidsson et al., 2002; } \\
\text { Kreuzberg et al., } 2010\end{array}$ \\
\hline $\begin{array}{l}\text { Traumatic brain } \\
\text { injury }\end{array}$ & ++ & ++ & $\begin{array}{l}\text { Ramaswamy et al., 2005; } \\
\text { Goings et al., } 2004\end{array}$ \\
\hline Alzheimer & -- & $? ?$ & Rodriguez et al., 2009 \\
\hline
\end{tabular}

New neuroblasts migrate to the affected areas in some of these diseases.

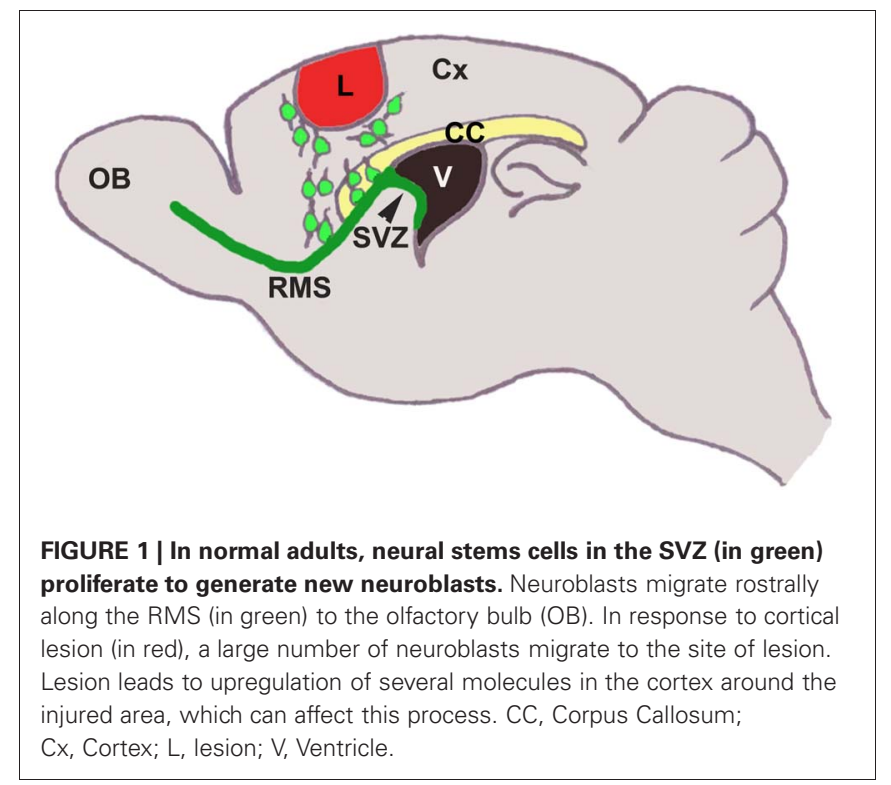

(Lois et al., 1996). Once in the OB, these neuroblasts switch from tangential to radial orientation and migrate individually and differentiate into the granule and periglomerular cell layers of the OB. Following cortical lesion, the ectopic migrating neuroblasts from the SVZ to the damaged cortical region may possibly lose chainlike conformation and migrate individually. In support of this proposition, it was observed that chain formation is affected after ischemic injury and cells migrating to the striatum appear to be more dispersed (Jin et al., 2003). It is also suggested that ectopic migration of the SVZ neuroblasts is at the expense of cells migrating to the $\mathrm{OB}$ along the RMS. Indeed, 4 days after aspiration lesion in the cortex, a reduction in forward migration of retrovirus-labeled SVZ neuroblasts was observed with a concomitant presence of labeled cells in the corpus callosum (Goings et al., 2004). In the next section, we will discuss different features of ectopic migration and the factors/mechanisms regulating this process. Although these factors are necessary, it is still unclear whether any single factor is sufficient to regulate migration as each of these factors seems to contribute only partially to this process.

\section{VASCULATURE AS MIGRATORY "RAILROAD"}

One of the major structures that assist neuroblasts' migration from the SVZ to the OB is blood vessels. In the RMS, blood vessels are oriented in parallel with neuroblasts as opposed to cortex, where vessels exhibit extensive reticular network. The role of vasculature in the neuroblasts migration along the RMS (tangential migration) as well as in the OB (radial migration) has been previously demonstrated (Bovetti et al., 2007; Whitman et al., 2009). Transplantation of neural cell lines into newborn mouse pups followed by time lapse imaging showed that neuroblasts indeed can migrate along the blood vessels in the brain parenchyma (Honda et al., 2007). A more recent study in newborn animals has shown that GFP-labeled neuroblasts can migrate radially to the cortex and that this migration is assisted by blood vessels (Le Magueresse et al., 2011). Two lines of observations suggest that in cortical 
lesion blood vessels can act as a scaffold for neuroblasts migrating within the cortex. First, thermocoagulation lesion of the cortex induces an increase in the endothelial cell proliferation followed by expansion of vascular tree at the level of the SVZ after 7 days of injury (Gotts and Chesselet, 2005). Second, in cerebral ischemia, neuroblasts are shown to migrate from the SVZ to the areas of infarct in close association with blood vessels (Ohab et al., 2006; Yamashita et al., 2006; Thored et al., 2007; Kojima et al., 2010).

\section{KEY MOLECULAR PLAYERS OF LESION-INDUCED ECTOPIC MIGRATION}

The molecular factors that regulate post-injury neuroblast migration can be classified as either chemokinetic or chemoattractive (Figure 1).

Reelin is a major chemokinetic molecule regulating cortical migration in response to lesion. Apart from its role in the cortical layer formation in the developing brain (D'Arcangelo et al., 1995), reelin also acts as a detachment signal for the RMS neuroblasts in the OB (Hack et al., 2002). Endogenous reelin has been shown to be upregulated transiently in the cortex following thermocoagulation lesion of the blood vessels of the pia matter (Courtès et al., 2011). Increased ectopic migration and recruitment of neuroblasts to the site of lesion was shown in transgenic mice overexpressing reelin in demyelination lesion model. The authors suggested that reelin regulates detachment of neuroblasts from the RMS and their dispersal in the corpus callosum in response to lesions, which in turn potentiates chemoattraction by different cytokines and mobilization of cells to the lesion site (Courtès et al., 2011).

Several molecules act as chemoattractants during ectopic migration of SVZ-derived neuroblasts. Chemoattractive role of Shh is known in regulating the migration of neuroblasts along the RMS (Balordi and Fishell, 2007; Angot et al., 2008). Angot and colleagues have shown that transplantation of Shh overexpressing QT6 cell line into the dorsal telencephalon resulted in deviation of migratory progenitors from the RMS to the telencephalon. Post-lesion, chemoattractive effect of Shh could be mediated by reactive astrocytes. This is because (a) lesion causes induction of Shh expression in astrocytes (Amankulor et al., 2009) and (b) in cerebral ischemia, neuroblasts migrating to the striatum were found to be closely associated with reactive astrocytes (Yamashita et al., 2006).

Another signaling mechanism that can regulate astrocyteassisted neuroblast migration is the interaction between chemokine receptor CXCR4 and its ligand Stromal cell-derived factor-1 (SDF-1). SDF-1 is shown to be intensely expressed by purified cortical astrocytes and weakly by neurons (Ohtani et al., 1998). Its receptor, CXCR4 is also expressed by these cells (Ohtani et al., 1998). Previous studies have shown that SDF-1/CXCR4 signaling regulates migration of neuroblasts along the RMS (Kokovay et al., 2010) and also pre-cerebellar neuron migration (Zhu et al., 2009). CXCR4 is not expressed in radially migrating neurons of the developing neocortex and so is unlikely to regulate this process (Stumm et al., 2003). However, significant upregulation of both SDF-1 and CXCR4 around the lesion area hints toward a possible role in ectopic neuroblasts migration. This is further supported by observations in different injury models. Indeed, involvement of SDF-1/CXCR4 signaling pathway in neuroblast migration to striatum in response to ischemia is well documented (Imitola et al., 2004; Robin et al., 2006). In a seizure model, functional blockage of CXCR4 by a specific antagonist AMD3100 has revealed that migration of embryonic stem cell-derived neural progenitors transplanted into dentate gyrus is attenuated (Hartman et al., 2010). Previously it was reported that Shh and SDF-1 act synergistically to control proliferation of cerebellar granule precursor cells (Klein et al., 2001). Therefore, it would be of interest to investigate whether a similar synergistic relationship is also present between these two signaling pathways in regulating ectopic neuroblasts migration as both these signaling molecules are expressed by reactive astrocytes.

Determining the precise role of different guidance cue molecules is still out of reach and previous reports are only indicative. Chemorepellent role of Slit1-Robo2 signaling in tangential migration of neuroblasts along the RMS is well-established. Slit1 expressing neuroblasts are repelled by Robo2 expressing glial tube astrocytes and thus maintain the compact tubular structure of the RMS (Kaneko et al., 2010). Slit1 present in the CSF forms a chemorepulsive gradient by beating of ependymal cell cilia and thus regulates forward movement of the neuroblasts (Sawamoto et al., 2006). Chemorepulsion could be a deterrent to an effective repair process as it can inhibit axon regeneration after lesion. mRNA expression analysis of members of slit family genes was carried out in the mouse model of cryo-injury (Hagino et al., 2003). A strong but transient expression of Slit2 mRNA was observed around the lesion area, whereas expression of Slit1 and Slit3 mRNAs was insignificant. Expression pattern analysis of the corresponding receptor molecules may shed light into the functional significance of such gene expression changes in the lesion model. Another secreted chemorepellant, SemaIII, was found to be expressed in the fibroblasts near the lesion core in the cortex (Pasterkamp et al., 1999). SemaIII expression creates a zone of exclusion for regenerating axons. Thus, it appears that increased expression of chemorepellant molecules near the lesion area probably acts as negative regulator of endogenous repair process.

\section{WHAT CELL TYPES ARE GENERATED UPON PROGENITOR DIFFERENTIATION?}

For an effective endogenous repair process it is important that the endogenous neuroblasts migrating to the site of lesion in the cortex differentiate into projection neurons and be able to restore endogenous function. Unfortunately, existing data regarding this aspect is not very encouraging. In the normal adult brain, SVZ progenitors are neurogenic and do not generate glia (Marshall et al., 2003). Yet, several reports indicate that after lesion ectopic precursor cells in the cortex predominantly form glia. In CCI injury model, the progenitor cells mostly form GFAP+ astrocytes near the injury site (Kernie et al., 2001) and occasionally differentiate into mature neurons (Salman et al., 2004). A previous study has also demonstrated that transplanted neural progenitor cells in TBI, which survive up to 1 year, are oligodendrocyte in nature (Shear et al., 2004). This observation was further strengthened in a study where ectopic transplantation of purified 
neuronal precursors (expressing Dcx, Tuj1 and GAD65/67) from the SVZ into cerebral motor cortex predominantly formed astrocytes and oligodendrocytes (Seidenfaden et al., 2006). Recently, it was shown that in demyelination lesions, SVZ neuroblasts express glial proteins and that this expression is mediated by chordin, a BMP antagonist (Jablonska et al., 2010). Thus, all these studies indicate that lineage plasticity, in its dormant state, is present among SVZ progenitor cells. Molecular changes following injury can trigger this property leading to cell fate switch in precursors migrating to ectopic regions.

Changes in the local tissue environment after lesion may possibly be an important determinant in fate decision. One prominent change in the cortex after lesion is the transient upregulation of oligodendrogenic transcription factor Olig2 (Buffo et al., 2005), but not neurogenic transcription factors such as Pax6, Mash1, Gsh2, or Ngn2. This suggests that the neurogenic response in the cortex following lesion remains unaffected. It appears that the balance between Olig2 and Pax6 is important in deciding cell fate, as repression of Olig2 expression induces Pax6 and enhances neurogenesis (Buffo et al., 2005). Shh may also play a crucial role in fate decision. During development, Shh controls development and specification of ventral subcortical telencephalon (Ericson et al., 1995) and regulates oligodendrocytes specification in this region (Nery et al., 2001; Tekki-Kessaris et al., 2001). Following lesion, upregulation of Shh expression in the cortex may also inhibit neuron formation and facilitate glial differentiation.

\section{OTHER ESSENTIAL FACTORS REGULATING REPAIR PROCESS}

Both physical exercise and glial intervention can influence effective repair process following injury. Most of the previous studies have looked at the neuroprotective aspect of physical exercise, which is primarily mediated by the inhibition of injury-induced apoptosis (Kim et al., 2010). In FPI model in rats, post-injury voluntary running wheel exercise for 14 days induces resistance to oxidative protein damage by inhibiting Zif268, a protein regulating gene expression of proteasome complex. Zif268 is involved in degradation of cellular proteins and thereby acting as a physiological regulator of cell survival (Szabo et al., 2010). Does physical exercise also affect neurogenesis? In normal adults, physical exercise enhances neurogenesis only in the hippocampus, but does not affect the SVZ (Brown et al., 2003). van Praag et al. (1999) have shown that physical exercise increases neurogenesis in the mouse dentate gyrus. Enhanced hippocampal neurogenesis was also observed after a lesion in the sensorimotor cortex in rats (Wurm et al., 2007). Early exercise (treadmill running for 28 days) after cerebral ischemia reduces infarct volume in rats (Matsuda et al., 2011) indicating its involvement in proliferation and recruitment of cells in the damaged area. Exercise-induced increase in neurogenesis appears to be mediated by several neurotrophic factors. Exercise increases expression of NGF, BDNF, trkB, and FGF in the hippocampus of the normal adults (Neeper et al., 1995; Gomez-Pinilla et al., 1997; Widenfalk et al., 1999) as well as in the striatum of the ischemic animals (Ang et al., 2003; Kim et al., 2005; Matsuda et al., 2011). At present, there is no direct evidence demonstrating that exercise can enhance post-lesion SVZ neurogenesis. However, few studies indirectly indicate that possibility. NGF can increase progenitor proliferation in the SVZ (Fiore et al., 2002). In TBI in children, NGF concentration is increased in the cerebrospinal fluid (CSF) (Chiaretti et al., 2009) and can possibly influence SVZ proliferation by binding to its receptor TrkA expressed by the SVZ cells (Triaca et al., 2005). It should, therefore, be investigated whether post-injury exercise can also increase NGF concentration in the CSF.

Glial intervention in injury-induced repair process is primarily mediated by reactive astrocytes. Astrocytes play a bipartite role (neuroprotection as well as inhibition of axon regeneration) in injury-induced repair process. Neuronal survival depends on their interaction with astrocytes and, therefore, a neuroprotective role of astrocytes following brain injury is unambiguous. In moderate CCI model, ablation of proliferative reactive astrocytes resulted in severe neuronal degeneration and inflammation compared to control mice (Myer et al., 2006). Astrocytic protection against neuronal degeneration has been well-investigated in ischemic injury and was found to be multifactorial. Astrocytes prevent neurons from encountering severe post-injury metabolic insults/toxicity by scavenging oxygen free radicals, up taking extracellular glutamate and buffering extracellular $\mathrm{K}^{+}$(Chen and Swanson, 2003). However, axonal regeneration, an important step for effective repair process, is negatively affected by astrocytes. Glial scars, formed at the lesion site, prevent regrowth of axons into the lesion area (Rudge and Silver, 1990). Chondroitin sulfate proteoglycans (CSPGs) were shown to be the main culprits and expression of different CSPGs are upregulated by astrocytes at the lesion site (Jones et al., 2003; Tang et al., 2003; Silver and Miller, 2004; Yiu and He, 2006).

\section{CONCLUSION AND FUTURE DIRECTIONS}

A plethora of changes take place in the cortex, SVZ and nearby regions after cortical lesions. Dissecting out the different molecular pathways and their functional implication in this context is a mammoth task. Nevertheless, a comprehensive understanding of the changes in the expression of different regulatory molecules is mandatory to better define the complex nature of post-lesion cellular and molecular changes. Currently, the inability of endogenous neural precursors to differentiate into a significant number of mature and functional neurons is the biggest challenge. An alternative approach to endogenous repair is to provide living tissue/cells from an exogenous origin by means of transplanting either brain tissue (Gaillard et al., 2007, 2009; Gaillard and Jaber, 2011) or stem cells (Gaspard et al., 2008). The success of these procedures, however, depends on the detailed knowledge of changes occurring in the brain following injury. A combinatorial approach by providing stimulating factors necessary for endogenous precursor growth, migration, and neuronal differentiation as well as by supplying exogenous neuronal precursors may provide a promising avenue to successfully repair the brain following cortical lesions.

\section{ACKNOWLEDGMENTS}

This work is funded by grant from "Institut pour la Recherche sur la Moëlle épinière et l'Encéphale.” 


\section{REFERENCES}

Alagappan, D., Lazzarino, D. A., Felling, R. J., Balan, M., Kotenko, S. V., and Levison, S. W. (2009). Brain injury expands the numbers of neural stem cells and progenitors in the SVZ by enhancing their responsiveness to EGF. ASN Neuro. 1, 95-111.

Altman, J., and Das, G. D. (1962). Autoradiographic and histological evidence of postnatal hippocampal neurogenesis in rats. J. Comp. Neurol. 124, 319-336.

Alvarez-Buylla, A., and Nottebohm, F. (1988). Migration of young neurons in adult avian brain. Nature 335, 353-354.

Alvarez-Buylla, A., Theelen, M., and Nottebohm, F. (1988). Birth of projection neurons in the higher vocal center of the canary forebrain before, during, and after song learning. Proc. Natl. Acad. Sci. U.S.A. 85, 8722-8726.

Amankulor, N. M., Hambardzumyan, D., Pyonteck, S. M., Becher, O. J., Joyce, J. A., and Holland, E. C. (2009). Sonic hedgehog pathway activation is induced by acute brain injury and regulated by injuryrelated inflammation. J. Neurosci. 29, 10299-10308.

Ang, E. T., Wong, P. T., Moochhala, S., and Ng, Y. K. (2003). Neuroprotection associated with running: is it a result of increased endogenous neurotrophic factors? Neuroscience 118, 335-345.

Angot, E., Loulier, K., Nguyen-BaCharvet, K. T., Gadeau, A. P. Ruat, M., and Traiffort, E. (2008). Chemoattractive activity of sonic hedgehog in the adult subventricular zone modulates the number of neural precursors reaching the olfactory bulb. Stem Cells 26, 2311-2320.

Arvidsson, A., Collin, T., Kirik, D., Kokaia, Z., and Lindvall, O. (2002). Neuronal replacement from endogenous precursors in the adult brain after stroke. Nat. Med. 8, 963-970.

Baldauf, K., and Reymann, K. G. (2005). Influence of EGF/bFGF treatment on proliferation, early neurogenesis and infarct volume after transient focal ischemia. Brain Res. 1056, 158-167.

Balordi, F., and Fishell, G. (2007). Hedgehog signaling in the subventricular zone is required for both the maintenance of stem cells and the migration of newborn neurons. $J$. Neurosci. 27, 5936-5947.

Banasr, M., Hery, M., Printemps, R., and Daszuta, A. (2004). Serotonininduced increases in adult cell proliferation and neurogenesis are mediated through different and common 5-HT receptor subtypes in the dentate gyrus and the subventricular zone. Neuropsychopharmacology 29 450-460.

Barnea, A., and Pravosudov, V. (2011). Birds as a model to study adult neurogenesis: bridging evolutionary, comparative and neuroethological approaches. Eur. J. Neurosci. 34 884-907.

Bhardwaj, R. D., Curtis, M. A. Spalding, K. L., Buchholz, B. A., Fink, D., Björk-Eriksson, T. Nordborg, C., Gage, F. H., Druid, H., Eriksson, P. S., and Frisén, J. (2006). Neocortical neurogenesis in humans is restricted to development. Proc. Natl. Acad. Sci. U.S.A 103, 12564-12568.

Blizzard, C. A., Chuckowree, J. A., King, A. E., Hosie, K. A., McCormack, G. H., Chapman, J. A., Vickers, J. C. and Dickson, T. C. (2011). Focal damage to the adult rat neocortex induces wound healing accompanied by axonal sprouting and dendritic structural plasticity. Cereb. Cortex 21, 281-291.

Bovetti, S., Hsieh, Y., Bovolin, P. Perroteau, I., Kazunori, T., and Puche, A. C. (2007). Blood vessels form a scaffold for neuroblast migration in the adult olfactory bulb. J. Neurosci. 27, 5976-5980.

Brown, J., Cooper-Kuhn, C. M., Kempermann, G., van Praag, H., Winkler, J., Gage, F. H., and Kuhn, H. G. (2003). Enriched environment and physical activity stimulate hippocampal but not olfactory bulb neurogenesis. Eur. J. Neurosci. 17, 2042-2046.

Buffo, A., Vosko, M. R., Ertürk, D., Hamann, G. F., Jucker, M., Rowitch, D., and Goötz, M. (2005). Expression pattern of the transcription factor Olig2 in response to brain injuries: implications for neuronal repair. Proc. Natl. Acad. Sci. U.S.A. 102 18183-18188.

Busto, R., Dietrich, W. D., Globus, M. Y., Alonso, O., and Ginsberg, M. D. (1997). Extracellular release of serotonin following fluid-percussion brain injury in rats. J. Neurotraume 14, 35-42.

Carbonell, W. S., Maris, D. O., McCall, T., and Grady, M. S. (1998). Adaptation of the fluid percussion injury model to the mouse. $J$. Neurotrauma 15, 217-229.

Cayre, M., Canoll, P., and Goldman, J. E. (2009). Cell migration in the normal and pathological postnatal mammalian brain. Prog. Neurobiol. $88,41-63$.
Chen, X.-H., Iwata, A., Nonaka, M., Browne, K. D., and Smith, D. H (2003). Neurogenesis and glial proliferation persist for at least one year in the subventricular zone following brain trauma in rats. J. Neurotrauma 20, 623-631.

Chen, Y., and Swanson, R. A. (2003). Astrocytes and Brain Injury. $J$ Cereb. Blood Flow Metab. 23, 137-149.

Chiaretti, A., Barone, G., Riccardi, R., Antonelli, A., Pezzotti, P., Genovese, O., Tortorolo, L., and Conti, G (2009). NGF, DCX, and NSE upregulation correlates with severity and outcome of head trauma in children. Neurology 72, 609-616.

Chirumamilla, S. S., Sun, D., Bullock, M. R., and Colello, R. J. (2002). Traumatic brain injury induced cell proliferation in the adult mammalian central nervous system, J. Neurotrauma 19, 693-703.

Coronas, V., Bantubungi, K. Fombonne, J., Krantic, S. Schiffmann, S. N., and Roger, M. (2004). Dopamine D3 receptor stimulation promotes the proliferation of cells derived from the post-natal subventricular zone. J. Neurochem. 91, 1292-1301.

Courtès, S., Vernerey, J., Pujadas, L. Magalon, K., Cremer, H., Soriano, E., Durbec, P., and Cayre, M. (2011). Reelin controls progenitor cell migration in the healthy and pathological adult mouse brain. PLoS One 6:e20430. doi: 10.1371/journal.pone.0020430

Covey, M. V., Jiang, Y., Alli, V. V., Yang, Z., and Levison, S. W. (2010). Defining the critical period for neocortical neurogenesis after pediatric brain injury. Dev. Neurosci. 32, 488-498.

D’Arcangelo, G., Miao, G. G., Chen, S. C., Soares, H. D., Morgan, J. I. and Curran, T. (1995). A protein related to extracellular matrix proteins deleted in the mouse mutant reeler. Nature 374, 719-723.

Dash, P. K., Mach, S. A., and Moore, A. N. (2001). Enhanced neurogenesis in the rodent hippocampus following traumatic brain injury. J. Neurosci. Res. 63, 313-319.

Decressac, M., Prestoz, L., Veran, J., Cantereau, A., Jaber, M., and Gaillard, A. (2009). Neuropeptide Y stimulates proliferation, migration and differentiation of neural precursors from the subventricular zone in adult mice. Neurobiol. Dis. 34, 441-449.

Decressac, M., Wright, B., Tyers, P. Gaillard, A., and Barker, R. A. (2010). Neuropeptide Y modifies the disease course in the R6/2 transgenic model of Huntington's disease. Exp. Neurol. 226, 24-32.

Dempsey, R. J., and Kalluri, H. S. (2007). Ischemia-induced neurogenesis: role of growth factors. Neurosurg. Clin. N. Am. 18, 183-190.

Doetsch, F., García-Verdugo, J. M., and Alvarez-Buylla, A. (1997). Cellular composition and three-dimensional organization of the subventricular germinal zone in the adult mammalian brain. J. Neurosci. 17, 5046-5061.

Dunnett, S. B. (2009). Neural transplantation. Handb. Clin. Neurol. 95, 885-912.

Ericson, J., Muhr, J., Placzek, M., Lints, T., Jessell, T. M., and Edlund, T. (1995). Sonic Hedgehog induces the differentiation of ventral forebrain neurons: a common signal for ventral patterning within the neural tube. Cell 81, 747-756.

Fancy, S. P., Harrington, E. P., Yuen, T. J., Silbereis, J. C., Zhao, C., Baranzini, S. E., Bruce, C. C., Otero, J. J., Huang, E. J., Nusse, R., Franklin, R. J., and Rowitch, D. H. (2011). Axin2 as regulatory and therapeutic target in newborn brain injury and remyelination. Nat. Neurosci. 14, 1009-1016.

Fiore, M., Triaca, V., Amendola, T. Tirassa, P., and Aloe, L. (2002). Brain NGF and EGF administration improves passive avoidance response and stimulates brain precursor cells in aged male mice. Physiol. Behav. 77, 437-443.

Gaillard, A., Decressac, M., Frappe, I. Fernagut, P. O., Prestoz, L., Besnard, S., and Jaber, M. (2009). Anatomical and functional reconstruction of the nigrostriatal pathway by intranigral transplants. Neurobiol. Dis. 35, 477-488.

Gaillard, A., and Jaber, M. (2011). Rewiring the brain with cell transplantation in Parkinson's disease. Trends Neurosci. 34, 124-133.

Gaillard, A., Prestoz, L., Dumartin, B., Cantereau, A., Morel, F., and Jaber, M. (2007). Reestablishment of damaged adult motor pathways by grafted embryonic cortical neurons. Nat. Neurosci. 10, 1294-1299.

Gaspard, N., Bouschet, T., Hourez, R., Dimidschstein, J., Naeije, G., van den Ameele, J., EspunyCamacho, I., Herpoel, A., Passante, L., Schiffmann, S. N., Gaillard, A., and Vanderhaeghen, P. (2008). An intrinsic mechanism of corticogenesis from embryonic stem cells. Nature 455, 351-357.

Goings, G. E., Sahni, V., and Szele, F. G. (2004). Migration patterns of subventricular zone cells in adult mice 
change after cerebral cortex injury. Brain Res. 23, 213-226.

Goings, G. E., Wibisono, B. L., and Szele, F. G. (2002). Cerebral cortex lesions decrease the number of bromodeoxyuridine positive subventricular zone cells in mice. Neurosci. Letts. 329, 161-164.

Gómez-Pinilla, F., and Cotman, C. W. (1992). Transient lesion-induced increase of basic fibroblast growth factor and its receptor in layer VIb (subplate cells) of the adult rat cerebral cortex. Neuroscience 49, 771-780.

Gomez-Pinilla, F., Dao, L., and So, V. (1997). Physical exercise induces FGF-2 and its mRNA in the hippocampus. Brain Res. 764, 1-8.

Gotts, J. E., and Chesselet, M.-F. (2005). Vascular changes in the subventricular zone after distal cortical lesions. Exp. Neurol. 194, 139-150.

Hack, I., Bancila, M., Loulier, K., Carroll, P., and Cremer, H. (2002). Reelin is a detachment signal in tangential chain-migration during postnatal neurogenesis. Nat. Neurosci. 5, 939-945.

Hagino, S., Iseki, K., Mori, T., Zhang, Y., Hikake, T., Yokoya, S., Takeuchi, M., Hasimoto, H., Kikuchi, S., and Wanaka, A. (2003). Slit and glypican-1 mRNAs are coexpressed in the reactive astrocytes of the injured adult brain. Glia 42, 130-138.

Hartman, N. W., Carpentino, J. E., LaMonica, K., Mor, D. E., Naegele, J. R., and Grabel, L. (2010). CXCL12mediated guidance of migrating embryonic stem cell-derived neural progenitors transplanted into the hippocampus. PLoS One 5:e15856. doi: 10.1371/journal.pone.0015856

Hoglinger, G. U., Rizk, P., Muriel, M. P., Duyckaerts, C., Oertel, W. H., Caille, I., and Hirsch, E. C. (2004). Dopamine depletion impairs precursor cell proliferation in Parkinson disease. Nat. Neurosci. 7, 726-735.

Honda, S., Toda, K., Tozuka, Y., Yasuzawa, S., Iwabuchi, K., and Tomooka, Y. (2007). Migration and differentiation of neural cell lines transplanted into mouse brains. Neurosci. Res. 59, 124-135.

Imitola, J., Raddassi, K., Park, K. I., Mueller, F. J., Nieto, M., Teng, Y. D., Frenkel, D., Li, J., Sidman, R. L., Walsh, C. A., Snyder, E. Y., and Khoury, S. J. (2004). Directed migration of neural stem cells to sites of CNS injury by the stromal cell-derived factor 1alpha/CXC chemokine receptor 4 pathway. Proc. Natl. Acad. Sci. U.S.A. 101, 18117-18122.
Jablonska, B., Aguirre, A., Raymond, M., Szabo, G., Kitabatake, Y., Sailor, K. A., Ming, G., Song, H., and Gallo, V. (2010). Chordin induced lineage plasticity of adult SVZ neuroblasts after demyelination. Nat. Neurosci. $13,541-550$.

Jiang, W., Gu, W., Brannstrom, T., Rosqvist, R., and Wester, P. (2001). Cortical neurogenesis in adult rats after transient middle cerebral artery occlusion. Stroke 32, 1201-1207.

Jin, K., Sun, Y., Xie, L., Peel, A., Mao, X. O., Batteur, S., and Greenberg, D. A. (2003). Directed migration of neuronal precursors into the ischemic cerebral cortex and striatum. Mol. Cell. Neurosci. 24, 171-189.

Jones, L. L., Margolis, R. U., and Tuszynski, M. H. (2003). The chondroitin sulfate proteoglycans neurocan, brevican, phosphacan, and versican are differentially regulated following spinal cord injury. Exp. Neurol. 182, 399-411.

Kaneko, N., Marín, O., Koike, M., Hirota, Y., Uchiyama, Y., Wu, J. Y., Lu, Q., Tessier-Lavigne, M., AlvarezBuylla, A., Okano, H., Rubenstein, J. L., and Sawamoto, K. (2010). New neurons clear the path of astrocytic processes for their rapid migration in the adult brain. Neuron 67, 213-223.

Kernie, S. G., Erwin, T. M., and Parada, L. F. (2001). Brain remodeling due to neuronal and astrocytic proliferation after controlled cortical injury in mice, J. Neurosci. Res. 66, 317-326.

Kim, D., Ko, I., Kim, B., Kim, T., Kim, S., Shin, M., Kim, C., Kim, H., Kim, K., and Baek, S. (2010). Treadmill exercise inhibits traumatic brain injury-induced hippocampal apoptosis. Physiol. Behav. 101, 660-665.

Kim, M. W., Bang, M. S., Han, T. R., Ko, Y. J., Yoon, B. W., Kim, J. H., Kang, L. M., Lee, K. M., and Kim, M. H. (2005). Exercise increased BDNF and trkB in the contralateral hemisphere of the ischemic rat brain. Brain Res. 1052, 16-21.

Klein, R. S., Rubin, J. B., Gibson, H. D. DeHaan, E. N., Alvarez-Hernandez, X., Segal, R. A., and Luster A. D. (2001). SDF-1a induces chemotaxis and enhances Sonic hedgehoginduced proliferation of cerebellar granule cells. Development 128, 1971-1981.

Kojima, T., Hirota, Y., Ema, M., Takahashi, S., Miyoshi, I., Okano, H., and Sawamoto, K. (2010). Subventricular zone-derived neural progenitor cells migrate along a blood vessel scaffold toward the post-stroke striatum. Stem Cells 28, 545-554.

Kokaia, Z., Thored, P., Arvidsson, A., and Lindvall, O. (2006). Regulation of Stroke-Induced Neurogenesis in Adult Brain-Recent Scientific Progress. Cereb. Cortex 16, 162-167.

Koketsu, D., Mikami, A., Miyamoto, Y., and Hisatsune, T. (2003). Nonrenewal of neurons in the cerebral neocortex of adult macaque monkeys. J. Neurosci. 23, 937-942.

Kokovay, E., Goderie, S., Wang, Y., Lotz, S., Lin, G., Sun, Y., Roysam, B., Shen, Q., and Temple, S. (2010). Adult SVZ lineage cells home to and leave the vascular niche via differential responses to SDF1/CXCR4 signaling. Cell Stem Cell 6, 163-173.

Kornack, D. R., and Rakic, P. (2001). Cell proliferation without neurogenesis in adult primate neocortex. Science 294, 2127-2130.

Kreuzberg, M., Kanov, E., Timofeev, O., Schwaninger, M., Monyer, H., and Khodosevich, K. (2010). Increased subventricular zone-derived cortical neurogenesis after ischemic lesion. Exp. Neurol. 226, 90-99.

Le Magueresse, C., Alfonso, J., Bark, C. Eliava, M., Khrulev, S., and Monyer H. (2011). Subventricular zonederived neuroblasts use vasculature as a scaffold to migrate radially to the cortex in neonatal mice. Cereb. Cortex. doi: 10.1093/cercor/bhr302. [Epub ahead of print].

Leker, R. R., Soldner, F., Velasco, I., Gavin, D. K., AndroutsellisTheotokis, A., and McKay, R. D. (2007). Long-lasting regeneration after ischemia in the cerebral cortex. Stroke 38,153-161.

Lois, C., and Alvarez-Buylla, A. (1994). Long-distance neuronal migration in the adult mammalian brain. Science 264, 1145-1148.

Lois, C., García-Verdugo, J. M., and Alvarez-Buylla，A. (1996). Chain migration of neuronal precursors. Science 271, 978-981.

Lu, D., Mahmood, A., Zhang, R., and Copp, M. (2003). Upregulation of neurogenesis and reduction in functional deficits following administration of DEtA/NONOate, a nitric oxide donor, after traumatic brain injury in rats. J. Neurosurg. 99, 351-361.

Luskin, M. B. (1993). Restricted proliferation and migration of postnatally generated neurons derived from the forebrain subventricular zone. Neuron 11, 173-189.

Magavi, S. S. P., Leavitt, B. R., and Macklis, J. D. (2000). Induction of neurogenesis in the neocortex of adult mice. Nature 405, 951-955.

Marshall, C. A., Suzuki, S. O., and Goldman, J. E. (2003). Gliogenic and neurogenic progenitors of the subventricular zone: who are they, where did they come from and where are they going? Glia 43, 52-61.

Masuda, T., Isobe, Y., Aihara, N., Furuyama, F., Misumi, S., Kim, T. S., Nishino, H., and Hida, H. (2007). Increase in neurogenesis and neuroblast migration after a small intracerebral hemorrhage in rats. Neurosci. Lett. 425, 114-119.

Matsuda, F., Sakakima, H., and Yoshida, Y. (2011). The effects of early exercise on brain damage and recovery after focal cerebral infarction in rats. Acta Physiol. 201, 275-287.

Morris, D. C., Zhang, Z. G., Wang, Y., Zhang, R. L., Greg, S., Liu, X. S., and Chopp, M. (2007). Wnt expression in the adult rat subventricular zone after stroke. Neurosci. Lett. 418 , 170-174.

Mu, Y., Lee, S. W., and Gage, F. H. (2010). Signaling in adult neurogenesis. Curr. Opin. Neurobiol. 20, 416-423.

Myer, D. J., Gurkoff, G. G., Lee, S. M, Hovda, D. A., and Sofroniew, M. V. (2006). Essential protective roles of reactive astrocytes in traumatic brain injury. Brain 129, 2761-2772.

Neeper, S. A., Gómez-Pinilla, F., Choi, J., and Cotman, C. (1995). Exercise and brain neurotrophins. Nature 373, 109.

Nery, S., Wichterle, H., and Fishell, G. (2001). Sonic hedgehog contributes to oligodendrocyte specification in the mammalian forebrain. Development 128, 527-540.

Nicoleau, C., Benzakour, O., Agasse, F., Thiriet, N., Petit, J., Prestoz, L. Roger, M., Jaber, M., and Coronas, V. (2009). Endogenous hepatocyte growth factor is a niche signal for subventricular zone neural stem cell amplification and self-renewal. Stem Cells 27, 408-419.

Ohab, J. J., Fleming, S., Blesch, A., and Carmichael, S. T. (2006). A neurovascular niche for neurogenesis after stroke. J. Neurosci. 26, 13007-13016.

Ohtani, Y., Minami, M., Kawaguchi, N., Nishiyori, A., Yamamoto, J., Takami, S., and Satoh, M. (1998). Expression of stromal cell-derived factor-1 and CXCR4 chemokine receptor mRNAs in cultured rat glial and neuronal cells. Neurosci. Lett. $249,163-166$.

Parent, J. M., Vexler, Z. S., Gong, C., Derugin, N., and Ferriero, D. M. 
(2002). Rat forebrain neurogenesis and striatal neuron replacement after focal stroke. Ann. Neurol. 52, 802-813.

Pasterkamp, R. J., Giger, R. J., Ruitenberg, M.-J., Holtmaat, A. J. G. D., De Wit, J., De Winter, F., and Verhaagen, J. (1999). Expression of the gene encoding the chemorepellent semaphorin III Is induced in the fibroblast component of neural scar tissue formed following injuries of adult but not neonatal CNS. Mol. Cell. Neurosci. 13, 143-166.

Rakic, P. (2004). Neuroscience: immigration denied. Nature 427, 685-686.

Ramaswamy, S., Goings, G. E., Soderstrom, K. E., Szele, F. G., and Kozlowski, D. A. (2005). Cellular proliferation and migration following a controlled cortical impact in the mouse. Brain Res. 1053, 38-53.

Rice, A. C., Khaldi, A., Harvey, H. B., Salman, N. J., White, F., Fillmore, H., and Bullock, M. R. (2003). Proliferation and neuronal differentiation of mitotically active cells following traumatic brain injury. Exp. Neurol. 183, 406-417.

Robin, A. M., Zhang, Z. G., Wang, L., Zhang, R. L., Katakowski, M. Zhang, L., Wang, Y., Zhang, C. and Chopp, M. (2006). Stromal cell-derived factor 1alpha mediates neural progenitor cell motility after focal cerebral ischemia. J. Cereb. Blood Flow Metab. 26, 125-134.

Rodriguez, J. J., Jones, V. C., and Verkhratsky, A. (2009). Impaired cell proliferation in the subventricular zone in an Alzheimer's disease model. Neuroreport 20, 907-912.

Romanko, M. J., Rola, R., Fike, J. R., Szele, F. G., Dizon, M. L., Felling, R. J., Brazel, C. Y., and Levison, S. W. (2004). Roles of the mammalian subventricular zone in cell replacement after brain injury. Prog. Neurobiol. 72, 77-99.

Rudge, J. S., and Silver, J. (1990). Inhibition of neurite outgrowth on astroglial scars in vitro. J. Neurosci. 10, 3594-603.

Salman, H., Ghosh, P., and Kernie, S. G. (2004). Subventricular zone neural stem cells remodel the brain following traumatic injury in adult mice. J. Neurotrauma 21, 283-292.

Sawamoto, K., Wichterle, H., GonzalezPerez, O., Cholfin, J. A., Yamada, M., Spassky, N., Murcia, N. S., Garcia-Verdugo, J. M., Marin, O., Rubenstein, J. L., Tessier-Lavigne, M., Okano, H., and Alvarez-Buylla, A. (2006). New neurons follow the flow of cerebrospinal fluid in the adult brain. Science 311, 629-632.
Schäbitz, W. R., Steigleder, T., CooperKuhn, C. M., Schwab, S., Sommer, C., Schneider, A., and Kuhn, H. G. (2007). Intravenous brain-derived neurotrophic factor enhances poststroke sensorimotor recovery and stimulates neurogenesis. Stroke 38, 2165-2172.

Scharff, C., Kirn, J. R., Grossman, M., Mackils, J. D., and Nottebohm, F. (2000). Targeted neuronal death affects neuronal replacement and vocal behavior in adult songbirds. Neuron 25, 481-492.

Seidenfaden, S., Desoeuvre, A., Bosio, A., Virard, I., and Cremer, $\mathrm{H}$. (2006). Glial conversion of SVZderived committed neuronal precursors after ectopic grafting into the adult brain. Mol. Cell. Neurosci. 32, 187-198.

Shear, D. A., Tate, M. C., Archer, D. R., Hoffman, S. W., Hulce, V. D., Laplaca, M. C., and Stein, D. G. (2004). Neural progenitor cell transplants promote long-term functional recovery after traumatic brain injury. Brain Res. 1026, 11-22.

Silver, J., and Miller, J. H. (2004). Regeneration beyond the glial scar. Nat. Rev. Neurosci. 5, 146-156.

Sims, J. R., Lee, S., Topalkara, K., Qiu, J., Xu, J., Zhou, Z., and Moskowitz, M. A. (2009). Sonic hedgehog regulates ischemia/hypoxia-induced neural progenitor proliferation. Stroke 40, 3618-3626.

Sirko, S., Neitz, A., Mittmann, T., Horvat-Bröcker, A., von Holst, A., Eysel, U. T., and Faissner, A. (2009). Focal laser-lesions activate an endogenous population of neural stem/progenitor cells in the adult visual cortex. Brain 132, 2252-2264.

Stumm, R. K., Zhou, C., Ara, T., Lazarini, F., Dubois-Dalcq, M., Nagasawa, T., Hollt, V., and Schulz, S. (2003). CXCR4 regulates interneuron migration in the developing neocortex. J. Neurosci. 23, 5123-5130.

Sundholm-Peters, N. L., Yang, H. K., Goings, G. E., Walker, A. S., and Szele, F. G. (2005). Subventricular zone neuroblasts emigrate toward cortical lesions. J. Neuropathol. Exp. Neurol. 64, 1089-1100.

Szabo, Z., Ying, Z., Radak, Z., and Gomez-Pinilla, F. (2010). Voluntary exercise may engage proteasome function to benefit the brain after trauma. Brain Res. 1341C, 25-31.

Szele, F. G., and Chesselet, M. F. (1996). Cortical lesions induce an increase in cell number and PSANCAM expression in the subventricular zone of adult rats, J. Comp. Neurol. 368, 439-454.
Tang, X., Davies, J. E., and Davies, S. J. A. (2003). Changes in distribution, cell associations, and protein expression levels of NG2, neurocan, phosphacan, brevican, versican, V2, and tenascin-C during acute to chronic maturation of spinal cord scar tissue. J. Neurosci. Res. 71, 427-444.

Tattersfield, A. S., Croon, R. J., Liu, Y. W., Kells, A. P., Faull, R. L., and Connor, B. (2004). Neurogenesis in the striatum of the quinolinic acid lesion model of Huntington's disease. Neuroscience 127, 319-332.

Tekki-Kessaris, N., Woodruff, R. Hall, A. C., Gaffield, W., Kimura, S., Stiles, C. D., Rowitch, D. H. and Richardson, W. D. (2001). Hedgehog-dependent oligodendrocyte lineage specification in the telencephalon. Development 128, 2545-2554.

Thompson, W. G. (1890). Successful brain grafting. N.Y. Med. J. 51, 701-702.

Thored, P., Wood, J., Arvidsson, A., Cammenga, J., Kokaia, Z., and Lindvall, O. (2007). Long-term neuroblast migration along blood vessels in an area with transient angiogenesis and increased vascularization After Stroke. Stroke 38, 3032-3039.

Triaca, V., Tirassa, P., and Aloe, L. (2005). Presence of nerve growth factor and TrkA expression in the SVZ of EAE rats: evidence for a possible functional significance. Exp. Neurol. 191, 53-64.

Tureyen, K., Vemuganti, R., Bowen, K. K., Sailor, K. A., and Dempsey, R. J. (2005). EGF and FGF-2 infusion increases post-ischemic neural progenitor cell proliferation in the adult rat brain. Neurosurgery 57 , 1254-1263.

van Praag, H., Kempermann, G., and Gage, F. H. (1999). Running increases cell proliferation and neurogenesis in the adult mouse dentate gyrus. Nat. Neurosci. 2, 266-270.

Vessal, M., and Darian-Smith, C. (2010). Adult neurogenesis occurs in primate sensorimotor cortex following cervical dorsal rhizotomy. J. Neurosci. 30, 8613-8623.

Wang, X., Mao, X., Xie, L., Greenberg, D. A., and Jin, K. (2009). Involvement of Notch1 signaling in neurogenesis in the subventricular zone of normal and ischemic rat brain in vivo. J. Cereb. Blood Flow Metab. 29, 1644-1654.

Watanabe, T., Okuda, Y., Nonoguchi, N., Zhao, M. Z., Kajimoto, Y., Furutama, D., Yukawa, H., Shibata, M. A., Otsuki, Y., Kuroiwa, T., and
Miyatake, S. (2004). Postischemic intraventricular administration of FGF-2 expressing adenoviral vectors improves neurologic outcome and reduces infarct volume after transient focal cerebral ischemia in rats. J. Cereb. Blood Flow Metab. 24, 1205-1213.

Whitman, M. C., Fan, W., Rela, L., Rodriguez-Gil, D. J., and Greer, C. A. (2009). Blood vessels form a migratory scaffold in the rostral migratory stream. J. Comp. Neurol. 516, 94-104.

Widenfalk, J., Olson, L., and Thoren, P. (1999). Deprived of habitual running, rats downregulate BDNF and $\operatorname{TrkB}$ messages in the brain. Neurosci. Res. 34, 125-132.

Winner, B., Couillard-Despres, S., Geyer, M., Aigner, R., Bogdahn, U., Aigner, L., Kuhn, H. G., and Winkler, J. (2008). Dopaminergic lesion enhances growth factorinduced striatal neuroblast migration. J. Neuropathol. Exp. Neurol. 67, 105-116.

Wurm, F., Keiner, S., Kunze, A., Witte, O. W., and Redecker, C. (2007). Effects of skilled forelimb training on hippocampal neurogenesis and spatial learning after focal cortical infarcts in the adult rat brain. Stroke 38, 2833-2840.

Xiao, M. J., Han, Z., Shao, B., and Jin, K. (2009). Notch signaling and neurogenesis in normal and stroke brain. Int. J. Physiol. Pathophysiol. Pharmacol. 1, 192-202.

Yiu, G., and He, Z. (2006). Glial inhibition of CNS axon Regeneration. Nat. Rev. Neurosci. 7, 617-627.

Yamashita, T., Ninomiya, M., Hernandez Acosta, P., GarciaVerdugo, J. M., Sunabori, T., Sakaguchi, M., Adachi, K., Kojima, T., Hirota, Y., Kawase, T., Araki, N., Abe, K., Okano, H., and Sawamoto, K. (2006). Subventricular zonederived neuroblasts migrate and differentiate into mature neurons in the post-stroke adult striatum. J. Neurosci. 26, 6627-6636.

Young, C. C., Brooks, K. J., Buchan, A. M., and Szele, F. G. (2011). Cellular and molecular determinants of stroke-induced changes in subventricular zone cell migration. Antioxid. Redox Signal. 14, 1877-1888.

Zhang, R., Xue, Y. Y., Lu, S. D., Wang, Y., Zhang, L. M., Huang, Y. L., Signore, A. P., Chen, J., and Sun, F. Y. (2006). Bcl-2 enhances neurogenesis and inhibits apoptosis of newborn neurons in adult rat brain following a transient middle cerebral artery occlusion. Neurobiol. Dis. 24, 345-356. 
Zhu, Y., Matsumoto, T., Mikami, S., Nagasawa, T., and Murakami, F. (2009). SDF1/CXCR4 signaling regulates two distinct processes of precerebellar neuronal migration and its depletion leads to abnormal pontine nuclei formation. Development 136, 1919-1928.

Ziv, Y., Finkelstein, A., Geffen, Y., Kipnis, J., Smirnov, I., Shpilman,
S., Vertkin, I., Kimron, M., Lange, A., Hecht, T., Reyman, K. G., Marder, J. B., Schwartz, M., and Yoles, E. (2007). A novel immune-based therapy for stroke induces neuroprotection and supports neurogenesis. Stroke 38, 774-782.

Conflict of Interest Statement: The authors declare that the research was conducted in the absence of any commercial or financial relationships that could be construed as a potential conflict of interest.

Received: 10 February 2012; accepted: 19 March 2012; published online: 09 April 2012

Citation: Saha B, Jaber M and Gaillard A (2012) Potentials of endogenous neural stem cells in cortical repair. Front.
Cell. Neurosci. 6:14. doi: 10.3389/fncel. 2012.00014

Copyright (c) 2012 Saha, Jaber and Gaillard. This is an open-access article distributed under the terms of the Creative Commons Attribution Non Commercial License, which permits non-commercial use, distribution, and reproduction in other forums, provided the original authors and source are credited. 